\title{
An Empirical Analysis to Assess the Impact of Inconsistency of Exchange Rate on Share Market: A Case Study of London Stock Exchange
}

\section{Hossain SA*}

Teaching Assistant, London college of business management and Information technology, UK

\begin{abstract}
This study evaluated the impacts of inconstancy of exchange rate on the London Stock Exchange (LSE). An assessment of writing on inconstancy of exchange rate and stock exchanges was led coming about into detail of an observational model. The Regression model was utilized as a part of making the relationship between conversion standard instability and securities exchange execution. The study utilized month to month United Kingdom information for the period August, 2004 - July, 2014. The information recurrence chose guaranteed a sufficient number of perceptions. An extremely feeble relationship between money instability and the share trading system was affirmed. The exploration finding is upheld by past studies. US premium rates were found to have a positive effect on Market capitalisation. Also GBP volatility makes greater impact on the money supply.

This study prescribed that, since the United Kingdom securities exchange is not by any means presented to the negative impacts of inconstancy of exchange rate, government can utilize conversion scale as an arrangement device to pull in outside portfolio speculation. The feeble relationship between inconstancy of exchange rate and money markets proposes that the LSE could be advertised as a safe business for remote speculators. Nonetheless, financial specialists, investors and portfolio directors still need to be vigilant concerning the overflows from the remote swapping scale into money markets. Despite the fact that there is a powerless relationship between GBP inconstancy and stocks in United Kingdom, this does not so much imply that financial specialists and portfolio administrators require not screen the improvements between these two variables.
\end{abstract}

\section{Introduction}

\section{Rationale}

The trend of volatility has been regarded as one of most prominent difficulties or the UK economy in recent years. Despite the fact that exchange markets, various firms and various industries are working together for diminishing the GBP volatility, in the same way as, vitality worth producers mentioned lowering the costs with diverse arrangements, steadiness inside conversion scale also been regarded as a long shot. For UK, Instability additionally has made an economy dilemma and it is introducing the as lower weight currency against EURO. Volatility of currency is mainly functioning as an important reactor for the UK economy growth. Exchange rate unpredictability caused basically by the tsunami of structural movements in the worldwide economy. In most of the cases, it is influencing stocks too. It is exceptionally critical for strategy creators to comprehend the relationship between fluctuations of exchange rate and stock market. Likewise there are such a large number of debates around nature's domain also. Analyzing fluctuations of exchange rate will provide such important knowledge which will determine the factual impacts exchange rate on London Stock Exchange (LSE).

\section{Relevance to the management study}

The Exchange rate ideal has changed fundamentally inside most recent 100 years. Since the starting till now guidelines have changed namelessly. Just extravagant nations had fluctuating exchange rates and level cash a while ago. Anyway, by the end of the century the parameter has been changed. It is not any more similar to the recent past. It has now ended up more evident to try for a coasting conversion standard. To extra, these drifting trade rates have affected the stock exchanges not at all like different apparatuses of economy. In purpose of certainty, decision is significantly more confounded than some time recently. In the Bretton Wood framework, one of the significant concerns of approach producers is the vitality of unpredictability of exchange rates. This evident to be, a projecting adaptability of exchange rates framework. Instability of exchange rates has significant derivations inside financial commercial center, especially stock markets. Above analysis settled the point of exchange rate and share market importance for any kind of management. It is very much relevant to the management studies and therefore, the study significance is higher for study of management.

\section{Purpose of the project and achieving aim}

Various researches have proved that exchange rate fluctuation has impacted on the stock market. It has been regarded as one of the top priority of business and finance area. This has prejudiced researcher to involve a research on such subject. Researcher aims to define the impact of exchange rate fluctuation on LSE. Below objective and question certainly will provide a greater idea about the impacts.

\section{Research Objective}

Research objective is "to measure the impact of inconstancy of exchange rate on the London Stock Exchange (LSE)".

${ }^{*}$ Corresponding author: Hossain SA, Teaching Assistant, London college of business management and Information technology, United Kingdom, Tel: 07424920887; E-mail: ssahossain@gmail.com

Received September 29, 2015; Accepted October 26, 2015; Published November 15, 2015

Citation: Hossain SA (2015) An Empirical Analysis to Assess the Impact of Inconsistency of Exchange Rate on Share Market: A Case Study of London Stock Exchange. J Bus Fin Aff 4: 154. doi:10.4172/2167-0234.1000154

Copyright: (c) 2015 Hossain SA. This is an open-access article distributed under the terms of the Creative Commons Attribution License, which permits unrestricted use, distribution, and reproduction in any medium, provided the original author and source are credited. 


\section{Research question}

- Research question is "what the impact of inconstancy of exchange rate on the London Stock Exchange (LSE)?

\section{Structure}

The paper report is separated into 6 tiers. Introduction, is the essential portion is the that demonstrated the foundation besides assorted establishments for the work report including research background, research objective, research question and targets and the essentialness of the study. Literature Review is second portion which kept an eye out for the aide perspectives of research. Overview of LSE and exchange rate is the third portion that outlines LSE (London Stock Exchange) and exchange rate summary. Research methodology, is the fourth portion that explains the procedure of the research, research plan where the research method and technique moreover the parts of vital and optional research and information get-together have been tended to. Data presentation and analysis, is the fifth portion where data assortment is done and then analyzed accordingly. Discussion is the sixth portion where all the results are discussed and evaluated whether it matches the objectives or not. Conclusion is the section of the where researcher addresses the proposal and further proposal on the research to conclude the work (Figure 1).

\section{Literature Review}

\section{Introduction}

A few scholastics, for example, Ross [1,2] furnished speculations with evidences on exchange rate fluctuation and stock market. Not, one or the other has provided such important models that actually can identify the actual relationships of exchange and stock market. This chapter is divided into two parts. First researcher will present the theoretical base and provide the gathered empirical evidences of exchange rate fluctuations.

\section{Flow oriented model}

Relying on the grounds of microeconomics Flow oriented model was established. is focused around the grounds of microeconomics. Flow oriented model shows associating connection presence which runs from exchange rate to stock prices. As such, stock costs are influenced through fluctuations of exchange rate. Saleh [3] mentioned that flow oriented model involves that worldwide intensity along with offset of exchange points that are influenced through exchange rate. Thusly it makes influences the future and present expected association's money stream and qualities of the stock. Local currencies positive reception captures a floating framework can regulate organization's increase and aggressive execution of trading stocks [4]. In this manner they maintain their cost of stock. Joseph accepts it that it can affect the data and yield costs, intensity of associations which are influenced through progressions within return rate.

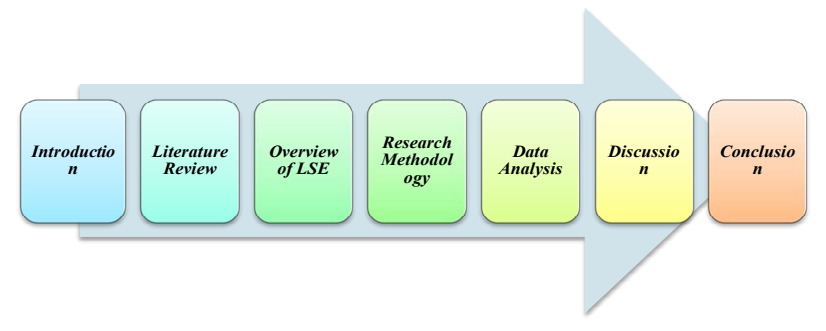

Figure 1: Structure of study.
Adverse consequences of exporters are conspicuous whether rate of trade. Subsequently, worldwide aggressiveness would be decreasing. Thusly, lessening benefit would influence the residential aggressiveness of the association. Resultantly, a discouraging correspondence between household money and stock cost might be perceived. In any case importing firms are profited if the trade rates acknowledge through encouraging the lessening in info costs. Low costs for the last items and administrations would be made by the decrease in expenses. Therefore benefits will be supported by the expanded deals. The appeal of the association in the residential securities exchange will build and the normal level of stock costs will be helped. Subsequently, the pattern of the effect relies on upon whether the organizations work essentially in an import or trading industry [3].

\section{Legitimacy of flow orient model's}

Aggarwal [5] mentioned about the flow orient model that it is backed through procurement of proof. Author also inspected the relationship of exchange rate and stock price. This concentrated the relationship of US exchange weighted conversion standard and US securities exchange files of every month within the period of 1974 and 1978. The optimistic correspondence within US securities exchange records and the exchange rate volatility is found in the study that presumes two variables are interrelated with a consistent style along with the flow orient model. In between the period of 1980 to 1986 , US dollar and US stock price maintained a link that is downbeat. This figure was achieved through the monthly figures [6]. This also represented the flow model. Casualty and cointegration research was used by Bahmani and Sohrabian [7] for investigating the exchange rate and stock price correlation. To add on it, Fang and Miller investigated same kind of research on Korea of a period 1997 to 2002. Bhattacharya and Mukherje, Chow, et al., Solnik, Young and Frank all established a verification that flow oriented model is not consistent [8-11].

\section{Stock oriented model}

In spite of the fact that the remote cash business is overwhelmed by the worldwide capital developments, a clear issue with the stream arranged model was brought up by Pilbeam [12] as being that they don't identify with the global monetary developments. This model's fundamental nature provides the capital record parity of installments. Money related record for determining the exchange rates were pushed by this stock oriented model. While exploring this stock oriented model, Adjasi and Biekpe confirmed the supply and request for possessions are likened through swapping scale. In this way, value developments of fiscally held holdings are affected altogether by the possibilities of relative money developments. In this manner swapping scale developments may affect or be affected by the stock value developments. Harmony of stock within currency business sector decides the supply and interest for coinage; the money related model suggests. Financial model distinguishes the swapping scale as a relative stake cost.

\section{Legitimacy of stock oriented model}

To a large extent, present value of asset is influenced by expected rate of return. Three variables that determine the exchange rate are relative national yield, relative cash supply and the relative premium rates. These variables also focuses on the on the stock trade rates. Friedman [13] established such financial model that incorporates the costs of stock. Friedman [13] has also outlined the interest determination for elevating the trading system of share. For accompanying capacity the model is demonstrated below $E\left(R_{i}\right)=R_{f}+\left[E\left(R_{m}\right)-R_{f}\right] x B_{i}$ 


$$
m_{t}=p_{t}+\alpha y_{t}-\beta i_{t}+\chi s_{t}
$$

\section{Portfolio balance model}

Portfolio balance model hypnotizes a negative relationship in between the exchange rate and costs of stock. It mainly expresses the effect of exchange rate on costs of stock. For building the interest strength and the stake of national and international, the part of trade rates and all-inclusive spread portfolios are assumed by the model Stavárek [14]. Using immediate and roundabout channel, the energy about residential coin is headed by an expand in local stocks costs. A conversion standard with a negative relationship is relied upon to be headed by stock cost since the local riches is lessened by decline in the stock cost, which thus prompts lower cash request and premium rates as far as the household prospect [15]. Along these lines one currency gratefulness and inflows of capital will be headed to the circumstance.

The accompanying mathematical statement exhibits the business sectors which the model comprises of; where the aggregate of outside securities if, residential securities $B$ and cash $M$ would characterize the aggregate riches $\mathrm{W}$. The model is

$$
W=M+B+e^{F}
$$

Welfens [16] mentioned that rather than the residential security markets, securities exchange is incorporated through a modified approach of portfolio offset.

\section{Practical validity of portfolio balance model}

Richard, et al. [17] examined the interface of exchange rate and costs of stock in Australia. While determining the exchange rate and costs of stock author involved the granger causality test and which clashed with the portfolio theory approach. Ajayi, et. al depicted the connection in between these two variables. Bahmani and Sohrabian [7] utilized the causality research for realising the connection in between the exchange rate and stock exchange. Many other authors like, frank and Young, Aggarwal $[5,11]$ used this model for realising the same relationship. However, Sonen and Hennigar [6] determined a negative association of this relationship.

\section{Hypothesis of efficient market}

The data that is accessible for securities and reflects on the costs of securities is known as efficient market hypothesis. This mainly works on the productivity of the capital market where handling data is initiated by theories. Security cost increases the value of characteristics. Kasper [18] commented that it creates effective business speculation.

\section{Practical validity of efficient market hypothesis}

Business like proof supportive EMH gets to be noticeable when return to of alterably overseen common stores is surpassed by the reappearance of business sector midpoints. The current stock costs after the report of a takeover in the UK has been considered by Firth (; cases Mandal [19]. Semi-solid structure effectiveness of (United Kingdom) securities exchange and the completely quick alteration for offering costs to their right levels were noticeable in the conclusion from study of Firth.

\section{Capital Asset Pricing Model (CAPM)}

Capital Asset Pricing Model (CAPM) is a model that actually works with a facilitating set for forecasting yield of the asset for the year. It was developed in the 60 's. Yield of the asset [ $\sigma 2]$ is displayed by the icon. This model explicates doubt about estimation where yield's standard deviation is charecterized [20]. Grosman and Livingstone mentioned that the mathematical statement CAPM is anticipated by the yield of stock. The model is

$$
E\left(R_{i}\right)=R_{f}+\left[E\left(R_{m}\right)-R_{f}\right] x B_{i}
$$

As per the solution, the yield got for initiating interest in danger free securities, $\mathrm{Rf}$ must equivalent the anticipated yield of any dubious stock i-E (Ri). The yield adjusted stands on an unsafe possession which is biased through precise factors.

\section{Validity of CAPM}

Roll evolved an empirical test with stock indicator and other features of markets and identified it as hard for empirical test. Taylor [21] also supported the critique of roll. Fama and McBeth (1973) found the correlation of risk and return which is positive. Taylor [21] suggested that their firm and market ratio was very much reliable and CAPM actually calculates the evident.

\section{The arbitrage pricing theory and its practical validity}

Drake and Fabozzi proposed the model APT (Arbitrage Pricing Theory) for Differentiating CAPM's market danger, one set of risky factors make impact on an advantage's normal yield. Model APT (Arbitrage Pricing Theory) creates a direct relationship of the yield on a basis of benefit with the $\mathrm{H}$ component. Vernimmen [22] mentioned that APT counts the Yield stock.

\section{Discussion}

From, above theories researcher found that Richard [17] examined the interface of exchange rate and costs of stock in Australia. While determining the exchange rate and costs of stock author involved the granger causality test and which clashed with the portfolio theory approach. Ajayi depicted the connection in between these two variables. Therefore, researcher followed portfolio model for this research paper.

\section{Empirical Analysis}

The conduct of unpredictability of stock exchange has been broadly contemplated utilizing the Regression structure spearheaded by Engel and further created by Bollerslev, and others. These studies endeavored to explore the relation of exchange rates and stock costs association within the rising monetary markets and industrialized nations. Notwithstanding, the aftereffects of some of these studies are uncertain. The present study might take a gander at studies that have been carried out in creating nations, developing markets and in created nations.

\section{Developing Countries}

Adjasi and Biekpe [12] researched the relationship between stock costs and swapping scale development in Ghana, South Africa, Egypt, Kenya, Mauritius and Nigeria. Vector Auto Regressive cointegration (VAR) was utilized by them and drive reaction investigation for focusing the short run linkage and long run linkage within stock costs and exchange rates. Long run relationship standard between stock costs and the conversion are discovered from their study in Tunisia, where swapping scale devaluation drove down stock costs. A short-run mistake adjustment display likewise demonstrated comparative results.

Adjasi, Harvey and Agyapong [12] utilized the Exponential Generalized Autoregressive Conditional Heteroskedascity (EGARCH) display in making the relationship between conversion standard unpredictability and securities exchange instability in Ghana. In their study, it was discovered that there was negative relationship 
between swapping scale unpredictability and securities exchange returns, deterioration in the nearby cash prompts a build in stock exchange returns over the long haul. Moreover, there was instability determination in the vast majority of the macroeconomic variables; current period's rate had an impact on conjecture change of future rate. It was likewise uncovered that an expand (diminish) in exchange shortfall and desire in future climb in exchange shortage will diminishing (build) stock exchange unpredictability. Furthermore, the buyer value file demonstrated a solid association with stock exchange instability. This implied that a build in buyer value prompted an ascent in securities exchange unpredictability. At long last, there was the vicinity of influence impact and instability stuns in stock profits for the Ghana Stock Exchange.

Pilinkus and Boguslauskas examined the short-run relationship between stock exchange costs and macroeconomic variables in Lithuania. One of their macroeconomic variables was swapping scale. The Augmented Dickey Fuller test was utilized to check the stationary of the chose time arrangement since a spurious relapse may happen if a period arrangement is not stationary. The study utilized the Impulse reaction capacity to test the presence of the short-run relationship between securities exchange costs and macroeconomic variables. As the consequences of the Impulse reaction capacity are dependable just with a stationary time arrangement the information was transformed into stationary after the second distinction. The consequences of the study unmistakably showed that macroeconomic variables are critical determinants at stock exchange costs in Lithuania. Their study presumed that unemployment rate, swapping scale, and transient premium rates adversely impact securities exchange costs. Through the Error Correction model, Subair and Salihu explored the impacts of exchange rateinstability on the Nigeria securities exchanges. It was observed that the swapping scale instability produced by means of GARCH procedure pushes a stronger negative effect on the Nigeria securities exchanges. Notwithstanding, the rate of swelling and premium rate did not have long run association with securities exchange promotion since the significant member in the business sector was the administration. In light of this, it was proposed that a facilitated money related and monetary strategy ought to be placed set up to check mate the vacillation of swapping scale so as to extend the profundity of the Stock Market.

Olugbenga analyzed the long-run and short-run impacts of exchange rate on stock exchange advancement in Nigeria in excess of 1985:1-2009:4 utilizing the Johansen cointegration tests. A bi-variate model was pointed out and observational results demonstrated a huge positive stock exchange execution to swapping scale in the short-run and a noteworthy negative stock exchange execution to conversion standard over the long haul. The Granger causality test indicated solid proof that the causation runs from swapping scale to securities exchange execution. This suggested that varieties in the Nigerian securities exchange are clarified by exchange rate instability. The study reasoned that the negative impact of exchange rate on Nigerian stock exchange execution could have been an aftereffect of overwhelming degrading of the coin since the presentation of the structural alteration program in 1986.

\section{General evaluation}

An investigation of studies from creating nations was directed and it was watched that there is no general accord concerning the connection between swapping scale and the stock exchange. Whilst a few studies found that swapping scale unpredictability pushes a stronger negative effect on the securities exchanges, others found that there is no relationship between these two variables. It was additionally watched that diverse studies connected distinctive methodologies to attain their targets. Confirmation of remarkable connections between trade rates and the stock exchange has been seen in various African nations. Notwithstanding, because of the distinctive approachs that were utilized by diverse studies furthermore the way that studies were directed in distinctive nations, diverse results could be acquired.

\section{Developing markets}

Murinde and Abdalla explored associations within stock cost and exchange rate among the rising monetary markets like, Philippine, Pakistan, Korea, India. The inspiration was to make the causal linkages between heading costs in the outside trade business sector and money markets; the linkages had suggestions for the on-going endeavors to create stock exchanges in rising economies all the while with an approach shift towards freely skimming trade rates. A bivariate vector autoregressive model was connected as an estimation strategy and the study utilized month to month perceptions on the IFC stock value list and the genuine viable swapping scale in excess of 1985:01 - 1994:07. Their finding has strategy suggestions; it recommended that separate governments ought to be mindful in their execution of swapping scale strategies, given that such approaches have repercussions on their securities exchanges.

The essential instinct behind Karoui's examination was that the instability of the stock returns could be incompletely clarified by the unpredictability of the money rates. The study concentrated on the accompanying 18 rising nations which are- Turkey, Thailand, Taiwan, South korea, South Africa, Russia, Philippines, Poland, Peru, Mexico, Malaysia, Indonesia, India, Hungary, Colombia, Chile, Brazil, Argentina. The study discovered a huge relationship between cash rate instability and stocks returns unpredictability for an expansive piece of the records mulled over. Additionally, a positive relationship between the outside conversion standard instability and the stock return unpredictability in an expansive piece of the division records concentrated on was found.

Spirits explored the degree of instability overflows between stock returns and exchange rate changes for six Latin American budgetary markets to be specific: Venezuela, Colombia, Chile, Brazil, Argentina and Mexico one European monetary market, and Spain in the 19982006 periods. The study partitioned the example into sub periods, before and after the presentation of the Euro and it connected the EGARCH technique to model unpredictability. The results demonstrated that the instability of stock returns influences the unpredictability of trade rates; nonetheless, no proof of instability transmission in the inverse course was found. The after effects of the study are predictable with those of Kanas and Yang and Doong who both discovered proof of instability overflows from stock comes back to trade rates. However the results vary on the proof of overflows in the inverse course from trade rates to securities exchanges. Spirits' study found that in spite of the fact that unpredictability overflows are substantially less pervasive from the different two-sided trade rates to the stock exchanges in the nations inspected, and also less steady crosswise over nations and about whether than the overflows from stock exchanges to trade rates.

Agrawal and Srivastav observationally inspected the motion between the unpredictability of stock returns and development of Rupee-Dollar trade rates, as far as the degree of interdependency and causality. Supreme estimations of information were changed over to $\log$ ordinary structures and checked for typicality. Application of Jarque-Bera test yielded facts that confirmed non-typical conveyance of 
both the variables. These postured inquiries on the stationary of the two arrangements. Stationary of the two arrangements was checked with ADF test and the results demonstrated stationary at level structures for both the arrangement. The coefficient of relationship between the two variables was registered, which showed slight negative connection between them. This cleared a path for deciding the course of impact between the two variables. Granger Causality test was connected to the two variables and it demonstrated unidirectional causality running from stock comes back to trade rates, that is, a build in the reappearances of Nifty brought on a decrease in the trade rates yet the opposite was not discovered to be genuine.

Eissa, Chortareas and Cipollini inspected the vicinity of unpredictability overflows between ostensible trade rates and stock returns in three nations: Egypt, Morocco and Turkey. The study considered day by day division files in Egypt, Morocco and Turkey. The multivariate GARCH show that was utilized did not deliver proof of cross-business sector impacts for the general stock lists returns. Anyway it was seen that a bidirectional stun and unpredictability overflows between trade rates and stock returns existed at the business division level. These discoveries were considerably more declared in Egypt and Turkey. The diverse results were because of the distinctive swapping scale administrations/approaches received by the three nations. While trade rates in Egypt and Turkey were permitted to buoy, Morocco took after an all the more firmly oversaw exchange rate administration.

In an alternate study in Turkey, Yildiz and Ulusoy inspected the impact of conversion standard unpredictability on Turkish stock returns utilizing month to month information for the period 19872010. The squared residuals from the Autoregressive Moving Average (ARMA) models were utilized to create a measure of exchange rate unpredictability and after that tried against Turkish stock returns. The month to month shutting file estimations of the Istanbul Stock Exchange 100 Index (ISE) were utilized as a part of request to acquire Turkish stock returns. The consequences of the study underlined that Turkish exporters did not consider exchange rate instability as a vital issue.

\section{General Evaluation}

Above observational investigation writing in developing markets demonstrated that there is no exact congruity among the studies directed to analyze the effect trade rates on securities exchange in developing markets. A few systems have been utilized with distinctive methodologies to test the connection between trade rates and the share trading system. Procedures, for example, the Engel-Granger Causality, Johansen Cointergration, GARCH, and ARMA were utilized by different studies. On the other hand, results from these studies are uncertain; there are blended results as to the connection between the two variables. There are differentiating results and a conclusion can't be attracted as to the relationship between conversion standard and stocks. This legitimizes the need of more research around there to help existing writing.

\section{Developed countries}

Aggarwal [5] inspected the relationship between trade rates and stock costs by taking a gander at the association between progressions in the US exchange weighted exchange rate and changes in US securities exchange records every month for the period 1974 to 1978. The study found that the exchange weighted exchange rate and the US securities exchange records were emphatically connected amid this period. The study reasoned that developments in the swapping scale could specifically influence the stock costs of multinational firms by impacting the estimation of its abroad operations, and in roundabout way impact household firms through affecting the costs of its fares and/ or its foreign made inputs.

Results demonstrated that nations like France, Germany, and Hong Kong don't display solid proof of positive commitment to swapping scale vacillations. This suggested that deteriorating neighborhood coinage are connected with climbing US stock exchanges, recommending a negative effect of exchange rate vacillations on the US/nearby value market association. Factual confirmation exhibited in Mun's study showed that higher exchange rate variability, generally, helped higher nearby value market instability however to a lower US value market unpredictability.

As far as their causality examination, Morales' results demonstrated an unidirectional causal relationship structure the trade rates to the stock costs on account of Hungary, Poland and Czech Republic. There was likewise proof of causality from the Hungarian exchange rateto the United Kingdom stock costs, from the Polish trade rates to the United Kingdom stock costs, from the Czech Republic exchange rateto the United Kingdom stock costs and from the Slovakian trade rates to the United Kingdom stock costs. At long last, the study likewise discovered proof of causality from the stock costs to the stock costs on account of Hungary to United Kingdom, United Kingdom to Poland, and the United States to Poland.

In an alternate study, Korsgaard analyzed the relationship between firm esteem and exchange return predictability in the accompanying European nations; Denmark, Spain and German. An alternate numerous relapse models was created and resultantly, the typical Ordinary Least Squared (OLS) technique was supplanted by the NeweyWest standard slips test. The information on Danish, Spanish and German organizations was synchronized such that the time compass went from May 2001 to October 2008. Conversion standard instability was tried against stock returns. The discoveries proposed that stock returns are to a certain degree delicate to swapping scale instability.

Sekmen inspected the impacts of exchange rate instability, utilizing the squared residuals from the autoregressive moving normal (ARMA) models, on stock returns for the U.S for the period 1980 to 2008. The study tried the impact of exchange rate unpredictability on the benefits of firms in the US utilizing the squared residuals from the ARMA model to create appraisals of unpredictability. In general, the study found that conversion standard instability adversely influenced US stock returns.

\section{Evaluation}

Table 1 explicates that a few studies, for example, those by Aggarwal [5] help the view that there is a relationship between exchange rate and stock exchanges. Others by Morales, Nieh and Lee [23] and Alagidede, Panagiotidis and Zhang demonstrate that there is no relationship between trade rates and the share trading system. The table also demonstrates that distinctive methods were utilized by diverse studies to acquire results. Studies utilized the EGARCH, Johansen system, Granger Causality Tests and the Autoregressive moving normal (ARMA), Regression models for estimation purposes. Diverse results were gotten in created nations. This may have been created by distinctive elements and diverse monetary circumstances that every nation was laid open to. Studies led in created nations are uncertain; the results are blended. From the table, it can be seen that Chi, Fang and Yang FU emphasises on the relationship of exchange rate and stock exchange can be followed up by either EGARCH or 
Regression analysis. This advocates this study in looking at the effect of swapping scale and securities exchange London.

\section{Overview of Exchange Rate Policy and LSE}

\section{Exchange rate history of UK}

Exchange rate administration ideal has changed fundamentally inside most recent 100 years. Since the starting till now principles have changed secretly. Just extreme nations had drifting trade rates and level cash awhile ago. However, the parameter changed by end of the century. It is no more like some time recently. It has now gotten to be clearer to try for a gliding exchange rate. To extra, these gliding trade rates have affected the securities exchanges dissimilar to different instruments of economy.

\section{A history of LSE (London Stock Exchange)}

One of the most seasoned stock trade businesses of the world is London Stock. It began exchanging more than 300 years back. London Stock Exchange quickly raised to wind up most vital monetary establishment of the City since Starting its life in the cafés of London in the seventeenth century, Years after years, London Stock Exchange has been reliably heading the method for developing a solid, generally directed securities exchange. By today it exists in the heart of the world monetary group. In 1995, it touched one of the breakthroughs including AIM (Alternative Money Investment ) into their administrations. In 2007, it developed with Borsa Italiana and shaped London Stock Exchange Group.

\section{Exchange rate policy and maintenance}

Exchange rate approach is a basic part of arrangement contentions identifying with worldwide intensity and macroeconomics concerns. Farrell and Todani, contend that developments in return rates can have a huge effect on financial development, vocation, expansion and the equalization of instalments and on the prosperity of people. Exchange rate progressions influence macroeconomic components, for example, expansion, monetary development, vocation creation and salary appropriation. Financial arrangement creators subsequently need to nearly screen exchange rate improvements to settle on the right choice. Exchange rate improvements are a critical part of the economy which the legislature should dependably stand watch on. The consequence of having unseemly conversion standard arrangements would be a misaligned Exchange rate. This misalignment has been rebuked for an arrangement of monetary fiascos endured by economies around the globe. Expand in globalization has likewise made the exchange rate approach to be one of the key determinants of both inner and outer strength. Exchange rate administration strategy of United Kingdom.

In UK, exchange rate administrations have developed from being altered, to oversee skimming lastly to free drifting in the year 2000 . The appropriation of the expansion focusing on administration in the year 2000 had suggestions on the way with which the swapping scale strategy is led. The Bank of England decided to direct expansion focusing on and having an adaptable exchange rate. The expansion focusing on skeleton, as in any state where it is connected has permitted the conversion scale to buoy and there are no exchange rate targets. Under an unadulterated expansion focusing on administration that the Bank of England decided to direct, the national bank has constrained control in the outside trade market. When the GBP devalued forcefully against the primary monetary forms, the Bank of England consistently abstained from interceding in the remote trade business sector to backing the GBP. The estimation of the GBP swapping scale was regardless is controlled by the strengths of interest and supply in the remote trade market. Despite the fact that the swapping scale is seen as an essential transmission system for fiscal approach that could influence swelling and financial development, the Bank of England is of the view that a lot of worry about conversion standard security can affect the wrong arrangement reaction.

The globalization process has permitted budgetary transactions and cash to moderately move crosswise over national limits and this has made the conversion scale to be a standout amongst the most critical instruments for dealing with the nation's economy. UK is no special case to this. Hentz (2005:18) prominent that exchange rate now be a standout amongst the most vital costs in the economy. As a consequence of this, general conversion standard arrangements are currently being coordinated to some proximate goals, including outside parity, interior offset, and micro financial productivity (Boker, Boraine, and Krafchik, 1993:138). The inquiry, nonetheless, of attaining proximate goals (for instance inside and outside offsets) are truly chosen by the decision of exchange rate administration.

The decision of Exchange rate administrations has been a focal choice confronting policymakers in very nearly all economies around the globe. The conversion standard has essential ramifications for exchange, inflation, Gross Domestic Products (GDP), budgetary markets and numerous different parts of the economy. Diverse exchange rate administrations could be worked to attain the picked targets these incorporate settled trade rates, free skimming and a mixed bag of halfway administrations, for example, movable peg or creeping peg.

\section{Economic Indicators of LSE}

Structural, administrative and mechanical changes over the previous decade have made the LSE to have numerous positive progressions. Numerous positive improvements have been recognized and as an aftereffect of this "the LSE is on the radar screen of numerous universal financial specialists today". Positive improvements have been portrayed by noteworthy changes in the financial pointers predominantly made out of, in addition to everything else, complete volume what's more estimation of shares exchanged on the LSE, All Share Index, Liquidity and business capitalisation. This area might inspect the patterns that have been going on the LSE in manifestation of graphical and numerical dissection. Graphical and numerical dissection serves to break down the patterns in the monetary markers on the LSE. This will give a measuring stick of assessing the general execution of the LSE. The aggregate volume and estimation of shares exchanged on the LSE, market capitalization, liquidity on the LSE, All Share Index are the monetary pointers broke down by this study.

\section{Research Methodology}

\section{Introduction}

This exploration expects to assess the effect of swapping scale instability on London Stock Market. Section 2 concentrated on writing audit of speculations and clarifications identified with the point. This part explains the philosophy to perform the examination. This predominantly incorporates the models and related variables picked for exploration, foreseen priori, research standard, information gathering and exact examination procedure of information.

\section{Style of Research}

\section{Research philosophy}

The term that portrays a change of learning and the way of 
information is known as exploration theory [24]. It impacts real perspective of the association in the middle of learning and the procedure through it is created. Saunders [24] specified around three examination methods of insight epistemology, philosophy and axiology.

\section{Epistemology}

Scientist should work from a position of common researcher when assets give information. At times, specialist might picked reality where information are considered as true. In this viewpoint scientist can contend that gathered information less open and therefore more target. All things considered, specialist would view question through sentiments and demeanour.

\section{Positivism}

One positivism system acknowledges the truth may be explored prevented from securing annoying the made case. This technique may be performed really if the reality of the situation is reliable (Levin, 1988). It has a couple of mixtures. Alavi and Carlson, communicated all trial investigates are positivist in nature.

\section{Interpretivism}

Saunders [24], said in regards to the examination rationale where expert commonly go about as a social performing craftsman to perceive change of human. It is known as Interpretivism. It generally focuses on human contrasts as opposed to considering matters like, machines. Remenyi, communicated that interpretivism has subjective point of view.

\section{Realism}

Saunders [24], raise legitimacy as an epistemological locus. Genuineness is focused on the inclination of truth. It truly infers that dissents subsist autonomously on individual's mind. Free identity of people is the center motivation behind legitimacy theory.

\section{Pragmatism}

The rationale that stands amidst a position of interpretivism and positivism is known as calm mindedness. It practices focused solicitation for the examination. Solicitation may be seen as an ongoing strategy. Segregating deduction picks waverings and request and over the long haul attested in topple. Saunders [24], said there is no true position to get.

\section{Chosen philosophy}

Fundamental objective of the momentum exploration is to discovering effect of swapping scale instability. This money based paper will be examining optional information which are true and accessible. Enough measure of learning is accessible is around also. Consequently scientist likes to work with epistemological reasoning.

This exploration objective affirms that examination conducts both subject and item. Therefore the flow examination affirms that it remains in an in the middle of positivism and interpretivism and practices center request and discriminating thinking. Along these lines the analyst plans to practical methodology of epistemological reasoning.

\section{Research approach}

Ghauri and Gronhaug, expressed that while channeling an exploration scientist needs to spare the apparent information without any preference. Result may match supremely with speculations and laws perceived around. Exploration methodology is required so as to discover reality and false and finishing the examination.

\section{Inductive}

An inductive technique of investigation is performed with down to business annotations by re-searcher. Contingent upon it, researcher improvises distinctive hypotheses, begins new theories and adds them to routine speculations. Grazino communicated that this procedure remains closer to the recouped data and high-lights on incitation. As needs be new made hypotheses could be all the more compelling.

\section{Deductive}

Bryman and Bell said that examiners fortifies theory from the open theories in deductive approach of investigation. Later on master performs the investigation and find precise results. Cooper and Schindler tagged that conclusions give the vital in deductive technique. Grazino et al. refered to that deductive approach principally focuses on the actuations recouped from theories. From speculations it starts and later on it is observationally investigated later on.

\section{Chosen approach}

Fundamental objective of the flow examination is to discovering effect of conversion standard instability. This money based paper will be inquiring about optional information which are genuine and accessible. Enough measures of information and speculations are accessible around too. Scientist does not expect to manufacture theory namelessly and build new hypothesis. As opposed to that, scientist likes to fabricate speculations on the premise of made hypothesis, inspect information and give genuine result. In this manner analyst will pick inductive methodology of exploration.

\section{Quantitative technique}

Quantitative technique for exploration predominantly depends on the strategy of information accumulation, dissect them and produce numeric information resultant. Results are clarified by diagrams or detail in this system for exploration [24]

\section{Qualitative strategy}

Qualitative strategy for examination mostly depends on the hypotheses and clarifications investigate them and create nonnumeric information resultant. Results are clarified by hypotheses and clarifications in this strategy for examination [24].

\section{The picked system}

Principle objective of the momentum examination is to discovering effect of conversion standard instability. This account based paper will be looking into auxiliary information which are genuine and accessible. Numeric examination will give conclusions. These will be clarified too. Accordingly scientist will pick both qualitative and quantitative technique for the exploration.

Saunders [24] referred to that there are 2 sorts of exploration techniques Specified routines change in the standings numeric and non-numeric information.

\section{Data Analysis}

\section{Analyse model}

So as to measure the effect of money unpredictability on the stock exchange in United Kingdom, this study emulated Subair's model. 
Subair utilized the regression model to explore the effect of swapping scale instability on money markets execution in London. His study utilized the accompanying model:

This present study might change Subair's model. The informative variables that are incorporated in this current study's model are: money supply (M3 )fares, GBP volatility, Market capitalization and US premium rates. The model should, in this way, take the structure:

\section{Lsmc $=\mathrm{f}(\mathrm{GBPVOL}, \mathrm{MC}, \mathrm{M} 3, \mathrm{USINT}$}

\section{Meaning of Variables}

LSMC is the characteristic logarithm of the stock exchange capitalisation (LSE). Market promotion is the piece of the pie value for every offer increased by the quantity of shares exceptional. Market underwriting will change in accordance with progressions in offer cost and the quantity of shares issued. Financial specialists focus an organization's offer esteem by taking a gander at its market promotion. Olalere held that, in United Kingdom, the conversion scale has a more noteworthy effect available promotion than stock costs. This is the motivation behind why market underwriting instead of stock costs is picked in this study.

Gbpvol is the US/GBP Exchange rate - The US dollar has been utilized as a part of perspective of the predominance of the dollar in universal transaction and also close connections between the United Kingdomn and US economies. Since 2001 the LSE execution takes after the GBP swapping scale.

M3 is utilized to catch cash supply. M3 is utilized to be a sign of the aggregate sum of cash supply accessible in the economy. $M$ is the broadest measure of cash thus it is utilized to gauge the whole supply of cash inside an economy. Bhattacharya and Mukherjee [8] likewise utilized this variable when they were leading a study on the way of the causal relationship between stock exchange and macroeconomic totals in India.

US investment rates - The expanded openness of the United Kingdomn economy permits the USA financial advancements to assume a urgent part in value costs in United Kingdom. The US premium rates have been assuming an immense part in deciding interest in developing markets. The LSE pulls in an extensive measure of remote investment from institutional financial specialists in the created world, including the US (Ocran, 2010). Subsequently changes (particularly diminishes in premium rates) in the US premium rates will make speculators to move far from the US and look for appealing venture ends of the line, for example, United Kingdom. Thus the United States investment rates are essential in clarifying the offer cost on the LSE.

\section{Expected priori}

Cash Supply - The indication of M3 is relied upon to be sure. Higher M3 additionally bestows additional liquidity to the securities exchanges since the overabundance cash is channelized into the stock exchanges, along these lines pushing up the business capitalisation. Thus, stock valuations climb as a quick response to an expand in M3. The productive business sector theory (EMH), as formalized by Fama [2], proposes that changes in macroeconomic variables, for example, cash supply can impact the conduct of securities exchange exercises. In an effective business, present and additionally past data on the development of these essential macro-variables are completely reflected in possession.

US investment rates: The US premium rates sign is required to be negative. A lessening in the US investment rate is relied upon to cause the stock costs to climb. When US premium rates fall, financial specialists move their speculation from the US to United Kingdom since it is a developing business sector. This build in speculation will result in the stock costs to climb because of the accessibility of numerous purchasers on the stock trade. In this way a negative relationship is relied upon to exist between the US premium rates and the stock exchange costs.

GBP Volatility: The indication of the GBP unpredictability is required to be negative. At the point when there is expanded unpredictability, speculators won't contribute much on stocks. It would be unsafe to contribute and they will take their venture somewhere else. This will result in stock costs to decline. Hence a negative relationship is perceived on the stock costs. Adjasi [12] (additionally discovered a negative relationship between conversion standard vacillations and the London securities exchange returns.

Information for the study should be acquired from optional sources, for example, the Johannesburg Stock Exchange and the United Kingdom Revenue Services, Statistics United Kingdom, United Kingdom Reserve Bank, and Department of Trade and Industry. Ostensible figures should be utilized for the study. The study utilizes month to month United Kingdom information for the period 2000 2010. The information recurrence chose should be month to month to guarantee a satisfactory number of perceptions. A perception lower than this (yearly or quarterly) won't give enough perception of which a solid conclusion might be drawn as the information won't be a sufficient representation of unpredictability while a higher recurrence will be influenced by impacts of settlements and clearing deferrals which influence returns over a shorter inspecting interims. The results from month to month data are more exact and are better equipped to catch the elements between trade rates and the LSE. The information should first test for stationary or the request of incorporation of the information arrangement keeping in mind the end goal to dispose of spurious relapse results. This should be carried out utilizing the Augmented Dickey Fuller system and the Phillip Peron test. This is the center of the following are

\section{The ADF Test}

Mernard held that the Dickey Fuller tests figure an autoregressive model and test whether the coefficient is measurably unique in relation to one. On the off chance that it is not, it will be important to distinction the arrangement to accomplish stationary. The Dickey Fuller test is of the model:

A significant issue with normal D.f test is that their discriminating qualities are pre dispositioned if there is autocorrelation in the residuals of the D-F relapse. To redress this, Dickey and Fuller (1981) concocted the increased rendition of the Dickey Fuller Test. They included the same number of slacked variables as important to evacuate any autocorrelation in the residuals. The ADF methodology controls for higher-request connection by including slacked contrasts terms of the ward variables to the right hand side of the relapse held that the Augmented Dickey Fuller will, then, take the structure: For the reasons of this study the Augmented Dickey Fuller is utilized.

\section{Phillips peron test}

In spite of the fact that the ADF is a standout amongst the most generally utilized tests5, it some of the time carries on inadequately, particularly in the vicinity of serial connection. As a consequence of this, Phillips and Peron created a more far reaching hypothesis of unit 
root non stationarity. The tests are like the ADF tests, however they fused programmed adjustment to the DF methodology to take into consideration auto correlated residuals. The Phillips Peron test performs better than (or at any rate and additionally) the ADF test regarding near force and yields tighter certainty interims. Notwithstanding this, the Phillips and Peron tests are non-parametic tests of the invalid of the unit root and are viewed as all the more influential, as they utilize reliable estimators of the change. The Phillips Perron unit root test contrasts from the ADF tests for the most part by the way they manage serial association and hetero scedasticity in the slips.

\section{Conclusion}

This part set out the model which decides the effect of money instability on stocks. Included in this model are variables that are liable to influence the operation of money markets. These variables are the local investment rates, US premium rates, GBP unpredictability, aggregate mining creation and fares. For stationarity/unit roots purposes, the model utilized the Dickey-Fuller and the Phillips Perron tests. Indicative tests, for example, the Normality test, Ramsey RESET test and the LM test were talked about. The regression system has been picked as the estimation method for the effect of coin unpredictability on money markets in United Kingdom. The succeeding section will run the talked about preparatory examination of the information and the last regression model utilizing the econometric bundle EVIEWS 7. At long last, demonstrative tests should be performed on the residuals.

\section{Data Analysis}

\section{Introduction}

The past section set the systematic structure and assessed the model and estimation methods to be utilized as a part of this study. This section introduces the primary aftereffects of relapse on month to month information for the period from August 2004 to July 2014. The effect of exchange rate inconstancy on stock exchange is evaluated utilizing three macroeconomic variables. It is through this part that the destination of this study might be accomplished. The fundamental target of this study has been to research the exchange rate inconstancy on the stock exchange in United kingdom.

This part is separated into 4 sub-segments. The primary exhibits the consequences of enlightening detail. This is done by descriptive statistics. This part has mainly followed the market capitalisation exchange rate fluctuation. The second part, Collinearity test, took after by stationarity tests for finding mean and variance change in the third area. Final test, regression is performed on the last part for finding the result of research question.

\section{Descriptive statistics of market capitalisation and exchange rate fluctuation in last 10 years}

Xuezheng, Rusell and Tiao held that numerous monetary arrangements, for example, returns on stocks and remote trade rates, show leptokurtosis and time-shifting unpredictability. These two gimmicks have been the subject of broad studies following the time when Mandelbrot (1963) and Fama (1965) initially reported them. In this respect it is important to perform some engaging facts to look at if the GBPvol and MC display time differing instability and leptokurtosis qualities. The two primary variables of the study are inspected in light of the fact that these variables focus the estimation system for the study. The facts of the GBPvol and MC arrangement are shown in Table 2 below.

\section{Descriptive Statistics}

Table 2 demonstrates the spellbinding detail of the GBPvol variable. Correspondingly, skewness and kurtosis speak to the way of flight from typicality. Emenike contends that in an ordinarily disseminated arrangement, skewness is 0 and kurtosis is 3 . The coefficient of skewness measures asymmetry. The GBPvol esteem for skewness is .462 and it reflects positive skewness. A positive skew demonstrates that the tail on the right side is longer than the left side and the majority of the qualities lie to the left of the mean. Additionally, if skewness is sure, the normal extent of positive deviations is bigger than the normal size of negative deviations. The coefficient of the GBPvol variable is showing that there is asymmetry within GBPvol. Thus, a variable that takes after a typical dissemination ought to be symmetric. The coefficient of kurtosis measures the peakedness of dissemination. The quality for kurtosis is -1.083 and this recommends that there is peakedness in the GBPvol. Kurtosis coefficients have values short of what 0. From this it could be watched that the GBPvol variable displays noteworthy deviations from ordinariness. The coefficient of kurtosis is -1.083 and it is more modest than zero. This shows noteworthy lerptokurtosis. A dissemination with a coefficient bigger than 3 is said to be leptokurtic and unified with a coefficient more modest than 3 is platykurtic. The $\mathrm{MC}$ variable reflects positive skewness with an estimation of 4.6 and this demonstrates that there is asymmetry in the MC variable. Defusco, Mcleavey, Pinto, Runkle (2006) held that a few specialists accept that speculators favour positive skewness, all else measure up to that is, they ought to lean toward portfolios with appropriations offering a moderately vast recurrence of uncommonly huge settlements. The

\begin{tabular}{|l|l|l|}
\hline Study & Methodology & Findings \\
\hline Choi, Fang and Yong Fu (2009) (New Zealand) & EGARCH & The exchange rate affected the stock market \\
\hline $\begin{array}{l}\text { Moracles (2007) (Czech republic, Hungary, } \\
\text { Poland and Slovakia) }\end{array}$ & $\begin{array}{l}\text { Regression Analysis, Johansen technique, } \\
\text { Cointegration, Vector Error, Correction Modelling and } \\
\text { the standard Granger Casuality test }\end{array}$ & $\begin{array}{l}\text { No evidence of stock prices and exchange rates moving } \\
\text { together either in the long-run or in the short-run was found. }\end{array}$ \\
\hline Alagidede, Panagiotidis and Zhang (2010) & Cointegration tests and Granger casuality test & There is no long-run relationship between two variables. \\
\hline Sekmen (2011) & ARMA & Exchange negatively stock returns rate volatility affected U.S \\
\hline
\end{tabular}

Table 1: Evaluation Studies

\begin{tabular}{|c|c|c|c|c|c|c|c|c|c|c|}
\hline & \multirow{2}{*}{$\begin{array}{c}\mathbf{N} \\
\text { Statistic }\end{array}$} & \multirow{2}{*}{$\begin{array}{c}\text { Minimum } \\
\text { Statistic }\end{array}$} & \multirow{2}{*}{$\begin{array}{c}\text { Minimum } \\
\text { Statistic }\end{array}$} & \multirow{2}{*}{$\begin{array}{c}\text { Mean } \\
\text { Statistic }\end{array}$} & \multirow{2}{*}{$\begin{array}{c}\text { Std. Deviation } \\
\text { Statistic }\end{array}$} & \multirow{2}{*}{$\begin{array}{l}\text { Variance } \\
\text { Statistic }\end{array}$} & \multicolumn{2}{|c|}{ Skewness } & \multicolumn{2}{|c|}{ Kurtosis } \\
\hline & & & & & & & Statistic & Std. Error & Statistic & Std. error \\
\hline GBP/USD & 119 & 1.42 & 2.07 & 1.7117 & .17257 & .030 & .462 & .222 & -1.083 & .440 \\
\hline $\begin{array}{l}\text { Market } \\
\text { Capitalization }\end{array}$ & 119 & 414193.00 & 793432.00 & 5689427.899 & 1.12448E5 & 1.264.E10 & .143 & .222 & 27.981 & .440 \\
\hline Valid N & 119 & & & & & & & & & \\
\hline
\end{tabular}

Table 2: Descriptive Statistics. 
estimation of kurtosis demonstrates that the MC variable has high circulation than a typical conveyance. The kurtosis worth is 27.981 and this demonstrates leptokurtosis.

From the month to month standard deviation, it might be seen that the MC is substantially more unpredictable than the Gbpvol henceforth there is requirement for it to be caught under the relapse model. Overall, both the Gbpvol and MC variables don't adjust to typical dissemination however show negative skewness and leptokurtic appropriations. Deviations from typicality of time arrangement information have been seen by past studies. Emenike watched that the Stock return arrangement don't fit in with typical appropriation yet show negative skewness and leptokurtic dispersion. Agrawal and Srivastava, likewise recognized that these variables are non-ordinarily dispersed.

\section{Finding the linear correlation between variables}

Collinearity Test: Collinearity was performed to see in there is no direct correspondence between illustrative variables. Rationale behind suspicion of no multicollinearity is if two variables are collinear it gets to be hard to divided the individual impact of every variable on the ward variable. So as to check multi collinearity among autonomous variables, a correspondence examination was performed. The closer the $r$ coefficient approaches \pm 1 , paying little mind to the course, the stronger is the current affiliation demonstrating a more straight relationship between the two variables. Notwithstanding, a recommended dependable guideline is that if the pair insightful relationship between two repressors is high, in abundance of 0.8 , multicollinearity may posture genuine issue. The association examination results are accounted for in Table 3 underneath.

Table 3 demonstrates that the most elevated relationship coefficient worth is 0.984 which is low. It is well beneath 0.8 . Since the most noteworthy correspondence numbers are higher than 0.8 , the results plainly demonstrate that none of the autonomous variables are exceptionally corresponded and multi collinearity amongst free variables exist.

\section{Finding the mean and changes in variance}

Stationarity test : On the off chance that the mean and fluctuation are consistent about whether, then the arrangement is stationary. Stationarity is vital for standard econometric hypothesis. Without it we can't get predictable estimators. One method for telling if a procedure is stationary is to plot the arrangement against time. Graphical representations taking the manifestation of time arrangement plots provide for us especially valuable methods for imagining data and leading similar dissects about whether. In the event that the chart crosses the mean of the specimen commonly, risks are that the variable is stationary; overall that is an evidence of diligent patterns far from the mean of the arrangement. On the off chance that the mean and difference change, then the arrangement is non-stationary. To identify if an arrangement is stationary graphical plots were carried out on watched estimations of the information. It demonstrates the GBPVOL and MC plots.

\begin{tabular}{|c|c|c|c|}
\hline \multirow{2}{*}{\multicolumn{2}{|c|}{ Model }} & \multicolumn{2}{|c|}{ Colinearity Statistics } \\
\hline & & Tolerance & VIF \\
\hline 1 & $\begin{array}{l}\text { Market } \\
\text { Capitalization } \\
\text { US interest rate } \\
\text { Money supply }\end{array}$ & $\begin{array}{l}.826 \\
\\
.984 \\
.821\end{array}$ & $\begin{array}{l}1.210 \\
1.016 \\
1.218\end{array}$ \\
\hline
\end{tabular}

Table 3: Elevated relationship coefficient.

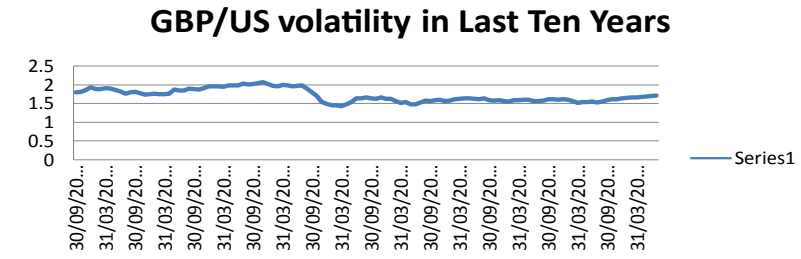

Figure 2: GBP/US Volatility in last ten years.

Market Capitalisation in last 10 years

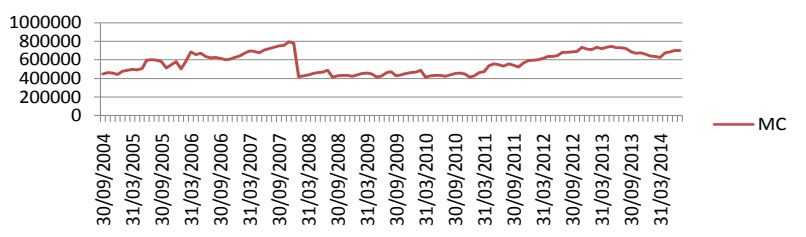

Figure 3: Market Capitalisation in last ten years.

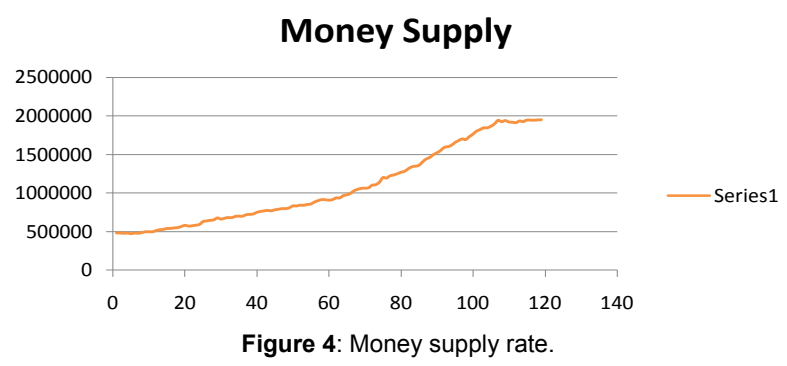

It proposes that the GBPVOL variable shows changes about whether. The level information demonstrates no propensity to come back to its mean demonstrating the requirement for differencing. The arrangement plot of the MC information shows that the arrangement is fluctuating about whether. This demonstrates that it is not stationary. The two variables have a period variation mean and change proposing that they are not stationary in their levels. The MC arrangement has a fluctuating conduct and with such a fluctuating example, a period arrangement is non-stationary, it doesn't demonstrate a propensity of mean inversion (Figure 2).

Graphical representations taking the manifestation of time arrangement plots was additionally done on the other informative variables; US premium rate, Money supply (M3). Their diagrams are shown in Figure 3 underneath.

Figure 4 demonstrates that the M3 information arrangement is emphatically straightly drifted and subsequently it is in this way nonstationary. The arrangement likewise demonstrates no inclination of coming back to its mean.

Figure 5 demonstrates that the Interest rate information arrangement is emitted and non- straightly drifted and subsequently it is stationary. The arrangement additionally demonstrates inclination of coming back to its mean.

Notwithstanding visual assessment, formal econometric tests were connected to unambiguously choose the genuine nature of time arrangement. Essential examination of graphical presentation of the information demonstrated conceivable non-stationary of the variables 


\section{Interest rate}

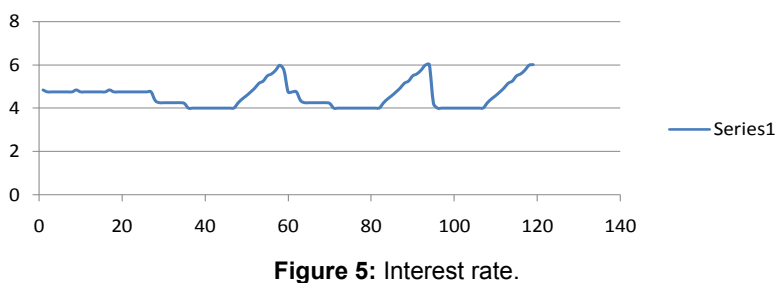

which encourages for unit root testing. This study emulated the standard methodology of unit root testing by utilizing the Augmented Dickey Fuller (ADF) test. Since the ADF test is regularly reprimanded for low power, the study supplements this test with the Phillips Perron (PP) test. Results from these tests are indicated in the tables underneath.

ADF test: In the event that the mean and change are consistent about whether, then the arrangement is stationary. Stationary is key for standard econometric hypothesis. Without it we can't get steady estimators. One method for telling if a methodology is stationary is to plot the arrangement against time. Graphical representations taking the type of time arrangement plots provide for us especially valuable methods for imagining data and leading similar examines about whether. On the off chance that the chart crosses the mean of the example ordinarily, risks are that the variable is stationary; overall that is an evidence of constant patterns far from the mean of the arrangement. In the event that the mean and fluctuation change, then the arrangement is non-stationary. To discover if an arrangement is stationary graphical plots were carried out on watched estimations of the information. Figure 2 demonstrates the GBPVOL and MC plots.

Figure 2 proposes that the GBPVOL variable shows vacillations about whether. The level information demonstrates no inclination to come back to its mean showing the requirement for differencing. The grouping plot of the MC information shows that the arrangement is fluctuating about whether. This demonstrates that it is not stationary. The two variables have a period variation mean and fluctuation recommending that they are not stationary in their levels. The MC arrangement has a fluctuating conduct and with such a fluctuating example, a period arrangement is non-stationary, it doesn't demonstrate a propensity of mean inversion.

Graphical representations taking the manifestation of time arrangement plots was additionally done on the other illustrative variables; POR, Export Money (M3).

It demonstrates that the M3 information arrangement is emphatically straightly slanted and henceforth it is along these lines non-stationary. The arrangement additionally demonstrates no propensity of coming back to its mean.

Notwithstanding visual review, formal econometric tests were connected to unambiguously choose the real nature of time arrangement. Essential investigation of graphical presentation of the information showed conceivable non-stationary of the variables which encourages for unit root testing. This study took after the standard strategy of unit root testing by utilizing the Augmented Dickey Fuller (ADF) test. Since the ADF test is regularly condemned for low power, the study supplements this test with the Phillips Perron (PP) test. Results from these tests are demonstrated in the tables underneath (Table 4).
The results from the ADF tests are given in tables. The results are organized as per level information arrangement and for first contrasts in the information arrangement.

Table 4 demonstrates that all variables were not stationary in levels. The $\mathrm{p}$ - estimations of the variables all being more noteworthy than 0.05 show that we couldn't dismiss the invalid theory of the presence of unit establish in levels for all variables. Be that as it may, the variables are stationary will be stationary after first differencing them. The greatness of the p-values (short of what 0.05 ) are huge, demonstrating that the variables are stationary from the start contras

PP Test: The results from the Phillip Perron test are given in Table 5 beneath.

In applying the Phillips Peron test to the variables, MC and TMP were discovered to be stationary at levels. On the other hand, the test detail of M3, POR, USINT and GBPVL were short of what the discriminating worth at $1 \%$ and $5 \%$ individually and subsequently not stationary. In any case, these variables achieved stationary after the first differencing. The discriminating qualities at $1 \%$ and $5 \%$ were 3.480818 and 2.883579 individually.

After the stationary tests, graphical plots were carried out to watch the way of the mean and difference of the stationary information. The graphical plots of the differenced variables are appeared.

It demonstrates that the initially differenced variables hint at coming back to its mean recommending that the arrangement is pitifully stationary. In the wake of differencing, the run arrangement plot shows that the information has a steady area and fluctuation, in spite of the fact that the example of the residuals demonstrates that the information leave from the model in a methodical way. The same is seen in the other four illustrative variables.

\begin{tabular}{|c|c|c|c|c|c|}
\hline \multirow{2}{*}{\multicolumn{2}{|c|}{ Variables }} & \multicolumn{2}{|c|}{ ADF test (intercept) } & \multicolumn{2}{|c|}{ ADF (Trend and intercept) } \\
\hline & & Levels & $1^{\text {ST }}$ Difference & Levels & $1^{\text {ST }}$ Difference \\
\hline \multicolumn{2}{|l|}{$\begin{array}{l}\text { M3 } \\
\text { (P value) }\end{array}$} & $\begin{array}{c}1.931176 \\
0.9998\end{array}$ & $\begin{array}{c}9.723775^{* *} \\
0.0000\end{array}$ & $\begin{array}{c}-2.274915 \\
0.4442\end{array}$ & $\begin{array}{c}-10.03535 \\
0.0000\end{array}$ \\
\hline \multicolumn{2}{|l|}{$\begin{array}{l}\text { GBPVOL } \\
\text { (P value) }\end{array}$} & $\begin{array}{c}2.224457 \\
0.1987\end{array}$ & $\begin{array}{c}8.076612^{* *} \\
0.0000\end{array}$ & $\begin{array}{c}-2.340393 \\
0.4090\end{array}$ & $\begin{array}{c}-8.085405 \\
0.0000\end{array}$ \\
\hline \multicolumn{2}{|l|}{$\begin{array}{l}\text { USINT } \\
\text { (P value) }\end{array}$} & $\begin{array}{c}-1.769695 \\
0.3941\end{array}$ & $\begin{array}{c}-4.679856^{* *} \\
0.0002\end{array}$ & $\begin{array}{c}-1.764772 \\
0.7162\end{array}$ & $\begin{array}{c}-4.670071 \\
0.0002\end{array}$ \\
\hline \multicolumn{2}{|l|}{$\begin{array}{l}\text { MC } \\
\text { ( } P \text { value) }\end{array}$} & $\begin{array}{c}-0.786105 \\
0.8191\end{array}$ & $\begin{array}{c}-6.921686^{* *} \\
0.0000\end{array}$ & $\begin{array}{c}-2.561822 \\
0.2985\end{array}$ & $\begin{array}{c}-7.155631 \\
0.0000\end{array}$ \\
\hline \multirow{2}{*}{$\begin{array}{l}\text { Critical } \\
\text { values }\end{array}$} & $1 \%$ & 3.480818 & 3.480818 & 4.036310 & 4.036310 \\
\hline & $5 \%$ & -2.885654 & -2.885654 & 3.447699 & 3.447699 \\
\hline
\end{tabular}

** and * denotes rejection of the null hypothesis at $1 \%$ and $5 \%$ respectively

Table 4: Unit root/stationary test: ADF test.

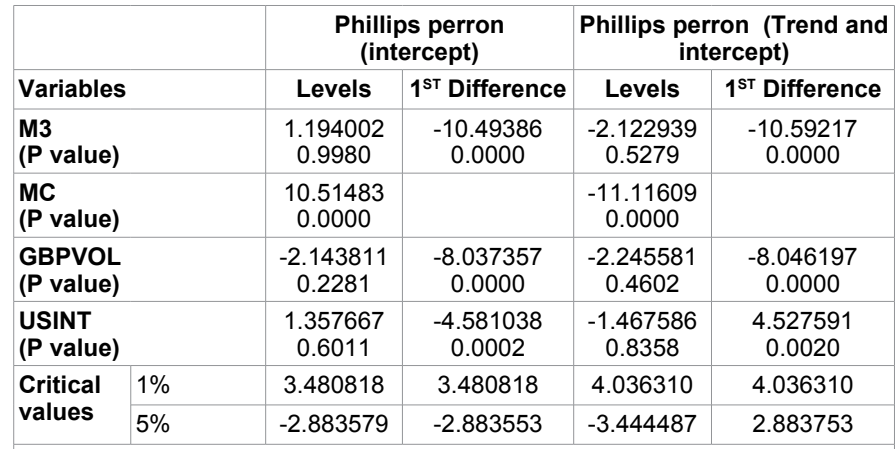

** and * denotes rejection of the null hypothesis at $1 \%$ and $5 \%$ respectively

Table 5: Unit root/Stationary tests: Phillips person tests. 


\section{Exchange rate vs Market capitalization}

Researcher performed regression analysis here. Researcher aimed to find the inconstancy of exchange rate impact on market capitalization. Picked invalid theory here is that there is no such association in the middle of enhancement of monetary position and availability to Market Capitalization. Reverse theory is that there is association in the middle of them. Utilizing SPSS programming figuring is carried out. Bivariate relapse examination results are demonstrated in above tables. Model rundown table gives $\mathrm{R} 2=$ to the relapse model. $\mathrm{R} 2$ delineates level of variety between two variables. If there should arise an occurrence of loaner's originations of change of their monetary circumstance for $88.6 \%$ of the aggregate variety in Market Capitalization. The ANNOVA table outlines the $\mathrm{F}$ degree planned for the relapse model. This detail assesses centrality of the facts for the general relapse. More prominent F proportion gives more noteworthy change inside the ward variable which is illuminated by the free variable. F degree here assigns the relapse show that is profoundly noteworthy at the 0.000 level. The relapse coefficient table demonstrates the dock named "Unstandardized Coefficients" uncovers the unstandardized relapse coefficient for better budgetary positions, 0.168 . T-test demonstrates the centrality level of relapse coefficient which is $(0.000)$ here. Investigation above rejects the invalid speculations that demonstrate existing associations in the middle of 2 variables which could be seen specifically above sober minded bend of total likelihood. Hence, it demonstrates that conversion standard instability has more noteworthy effect on Market Capitalization.

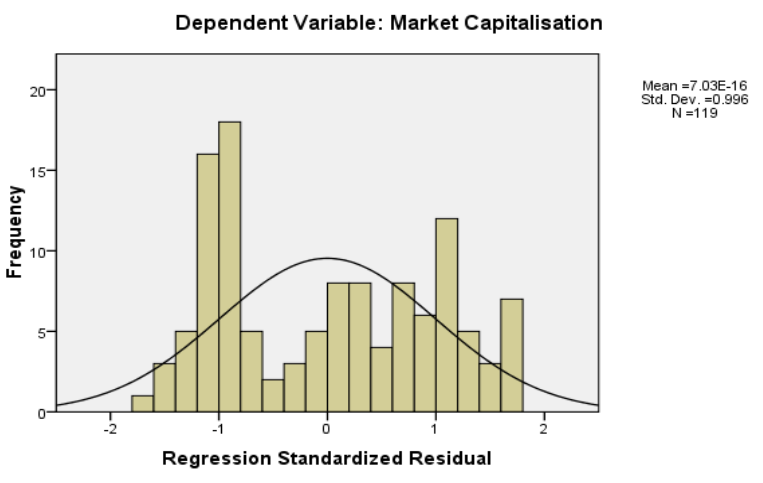

Figure 6: Exchange rate vs Market Capitalisation.

\section{Exchange rate vs Interest rate}

Researcher performed regression analysis here. Researcher aimed to find the inconstancy of exchange rate impact on Interest Rate. Picked invalid theory here is that there is no such association in the middle of enhancement of monetary position and availability to Interest Rate. Reverse theory is that there is association in the middle of them. Utilizing SPSS programming figuring is carried out. Bivariate relapse examination results are demonstrated in above tables. Model rundown table gives $\mathrm{R} 2$ = to the relapse model. $\mathrm{R} 2$ delineates level of variety between two variables. If there should arise an occurrence of loaner's originations of change of their monetary circumstance for $88.6 \%$ of the aggregate variety in Interest Rate. The ANNOVA table outlines the F degree planned for the relapse model. This detail assesses centrality of the facts for the general relapse. More prominent $\mathrm{F}$ proportion gives more noteworthy change inside the ward variable which is illuminated by the free variable. F degree here assigns the relapse show that is profoundly noteworthy at the 0.000 level. The relapse coefficient table demonstrates the dock named "Unstandardized Coefficients" uncovers the unstandardized relapse coefficient for better budgetary positions, 0.168 . T-test demonstrates the centrality level of relapse coefficient which is $(0.000)$ here. Investigation above rejects the invalid speculations that demonstrate existing associations in the middle of 2 variables which could be seen specifically above sober minded bend of total likelihood. Hence, it demonstrates that conversion standard instability has more noteworthy effect on Market Capitalization (Figure 6, Tables 6 and 7).

\section{Exchange rate vs Money Supply}

Researcher performed regression analysis here. Researcher aimed to find the inconstancy of exchange rate impact on market capitalization. Picked invalid theory here is that there is no such association in the middle of enhancement of monetary position and availability to Money Supply. Reverse theory is that there is association in the middle of them. Utilizing SPSS programming figuring is carried out. Bivariate relapse examination results are demonstrated in above tables. Model rundown table gives $\mathrm{R} 2$ = to the relapse model. $\mathrm{R} 2$ delineates level of variety between two variables. If there should arise an occurrence of loaner's originations of change of their monetary circumstance for the aggregate variety in Money Supply The ANNOVA table outlines the $\mathrm{F}$ degree planned for the relapse model (Figures 6 and 7). This detail assesses centrality of the facts for the general relapse. More prominent F proportion gives more noteworthy change inside the ward variable which is illuminated by the free variable. F degree here 3.740 assigns the relapse show that is profoundly noteworthy at the 0.000 level. The

\begin{tabular}{|c|c|c|c|c|c|c|c|c|c|}
\hline \multirow[t]{2}{*}{ Model } & \multirow[t]{2}{*}{$\mathbf{R}$} & \multirow[t]{2}{*}{ R Square } & \multirow[t]{2}{*}{ Adjusted R Square } & \multirow{2}{*}{$\begin{array}{l}\text { Std. Error of the } \\
\text { Estimate }\end{array}$} & \multicolumn{5}{|c|}{ Change Statistics } \\
\hline & & & & & $\begin{array}{l}\text { R Square } \\
\text { Change }\end{array}$ & F Change & df1 & df2 & Sig. F Change \\
\hline 1 & $.208^{a}$ & .043 & .035 & .56438 & .043 & 5.309 & 1 & 117 & .023 \\
\hline
\end{tabular}

a. Predictors: (Constant), GBP/USD

b. Dependent Variable: US Interest Rate

Table 6: Model Summary ${ }^{\mathrm{b}}$ of Exchange rate vs interest rate.

\begin{tabular}{|l|l|c|c|c|c|}
\hline Model & Sum of Squares & Df & Mean Square & Sig. \\
\hline \multirow{3}{*}{1} & Regression & 1.691 & 1 & 1.691 & .319 \\
\cline { 2 - 5 } & Residual & 37.268 & 117 & $.023^{\text {a }}$ \\
\cline { 2 - 5 } & Total & 38.959 & 118 & \\
\hline
\end{tabular}

a. Predictors: (Constant), GBP/USD

b. Dependent Variable: US Interest Rate 
relapse coefficient table demonstrates the dock named "Unstandardized Coefficients" uncovers the unstandardized relapse coefficient for better budgetary positions, 0.168 . T-test demonstrates the centrality level of relapse coefficient which is $(0.000)$ here. Investigation above rejects the invalid speculations that demonstrate existing associations in the middle of 2 variables which could be seen specifically above sober minded bend of total likelihood. Hence, it demonstrates that conversion standard instability has more noteworthy effect on Money Supply (Tables 8 and 9).

\section{Discussion and Conclusion}

The principle goal driving this study has been to analyze the effect of currency fluctuations on stocks market in United Kingdom. To accomplish this destination, a few appraisals were performed. Firstly, an outline of the advancements of the GBP and the stock exchange was carried out. An outline of the advancements of the GBP swapping scale and the share trading system was important as this gives a premise to our understanding of the reason for its fluctuation. The exchange rate in United Kingdom has been described by respectable fluctuation and these were seen to spill into money markets. Changes in the GBP have extensive impacts on the route with which the stock exchange works.

An evaluation of writing on exchange rate fluctuation and

Histogram

Dependent Variable: Money Supply (M3)

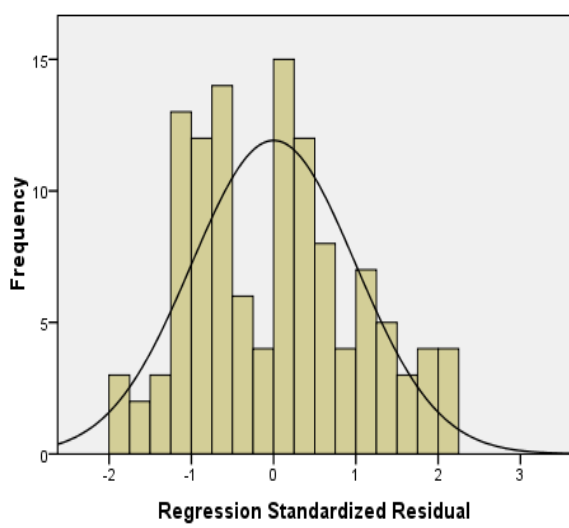

Mean $=-9.47 \mathrm{E}-16$
Std. Dev. $=0.996$
$N=119$

Figure 7: Exchange rate vs Money Supply securities exchanges was led and from it an exact model was tagged. It was seen that there is a blended supposition as to the relationship that exist between conversion scale and the share trading system. The study utilized month to month United Kingdom's information for the period August, 2004- July, 2014. The information recurrence chose guaranteed a satisfactory number of perceptions. The variables utilized within the study were GBP conversion standard, market capitalisation; supply of money (M3), and United States premium rate. Spellbinding facts were utilized to explore the factual properties of the two principle variables; exchange rate standard and business capitalisation. Results demonstrated that these two variables were absolutely skewed and notwithstanding this they had fat tails. The study utilized the regression model to measure the effect of exchange rate fluctuation on the share trading system of LSE.

\section{The imperative experiences of the results could be abridged as takes after}

To begin with, the examination reported powerless relationship between exchange rate fluctuation and the stock exchange. This result is not steady of the assumption that the instability encompassing conversion scale business sector misshapes proficient speculation distribution. Showcases that are presented to cash instability generally confront extensive vulnerability about the reappearances of venture ventures. This can prompt interruption of these organizations on stocks. Unpredictability influences the stream of data about the nature of undertakings to speculators and subsequently twists asset distribution.

Results from this study did not discover any confirmation that backing the above declaration. Actually, unpredictability was seen to bring positive effects on the stock exchange in United Kingdom. This may be a consequence of the accompanying;

1. The organizations on the LSE now understand the negative effects of coin unpredictability and thus have created measures that pad against the impacts of cash instability.

2. Cavallo held that "working together in an economy that is occasionally presented to turmoil in relative costs implies that business visionaries must face generous vulnerability about the benefit of option tasks. Under this situation, a key peculiarity is the capacity to adjust to a nature's domain". Organizations and firms working on the LSE have taken different instruments to fence against swapping scale hazard. Results from this study propose that the LSE has approached towards educational productivity in any event as for swapping scale and cash supply unpredictability. The frail relationship between money unpredictability and stocks appear to give prove that the LSE

\begin{tabular}{|c|c|c|c|c|c|c|c|c|c|}
\hline \multirow[t]{2}{*}{ Model } & \multirow[t]{2}{*}{$\mathbf{R}$} & \multirow[t]{2}{*}{ R Square } & \multirow[t]{2}{*}{ Adjusted R Square } & \multirow{2}{*}{$\begin{array}{l}\text { Std. Error of the } \\
\text { Estimate }\end{array}$} & \multicolumn{5}{|c|}{ Change Statistics } \\
\hline & & & & & $\begin{array}{l}\text { R Square } \\
\text { Change }\end{array}$ & F Change & df1 & df2 & Sig. F Change \\
\hline 1 & $.608^{\mathrm{a}}$ & .369 & .364 & 3.95317E5 & .369 & 68.474 & 1 & 117 & .000 \\
\hline
\end{tabular}

a. Predictors: (Constant), GBP/USD

b. Dependent Variable: Money Supply (M3)

Table 8: Model Summary ${ }^{b}$ of Exchange rate vs Money Supply.

\begin{tabular}{|l|l|c|c|c|c|}
\hline Model & Sum of Squares & Df & Mean Square & Sig. \\
\hline \multirow{2}{*}{1} & Regression & $1.070 \mathrm{E} 13$ & 1 & $1.070 \mathrm{E} 13$ & 68.474 \\
\cline { 2 - 5 } & Residual & $1.828 \mathrm{E} 13$ & 117 & $1.563 \mathrm{E} 11$ \\
\cline { 2 - 5 } & Total & $2.898 \mathrm{E} 13$ & 118 & \\
\hline
\end{tabular}

a. Predictors: (Constant), GBP/USD

b. Dependent Variable: Money Supply (M3) 
is not a proficient business sector. Results propose that organizations on the LSE can utilize swapping scale data to anticipate the future conduct of stocks. This results in the organizations' capability to gauge the developments that the GBP would take later on consequently empowering them to pad against the future variances of the GBP. As a consequence of this, money unpredictability won't influence the stock operations on the LSE.

3. The frail relationship between conversion scale unpredictability and the stock exchange may have been brought on by the diverse variables that influence each of these businesses. The variables/news that causes changes in return rates may be unique in relation to the components that cause changes in stock costs. Under such situation, there ought to be no connection between the said variables (Muhammad and Rasheed, 2011). On the off chance that there were normal elements that impact both swapping scale unpredictability and securities exchange, then a solid relationship between these two money related variables would have been found.

Second, stocks was seen to be influenced by other macroeconomic variables to be specific: premium rates, aggregate mining generation, cash supply and the United States premium rates. Premium rates were seen to have a negative effect on stocks. This is upheld both by monetary hypothesis and various studies including that of Alam and Uddin. Expands in premium rates builds the opportunity expense of holding cash and consequently substitution in the middle of stocks and enthusiasm bearing securities and thus falling stock costs. In different words, climbs in premium rates propel speculators to put less in stocks and this, subsequently, prompt a fall in business sector capitalisation.

Aggregate mining creation was likewise seen to have a negative effect on securities exchange capitalisation; a build altogether mining generation prompted a decrease in securities exchange capitalisation. A build in the supply of cash was seen to have a positive effect on the stock exchange. Expand in cash supply prompts build in liquidity that eventually brings about upward development of ostensible value costs. Li discovered a comparative bring about a study which evolved an examination of cash supply and stock exchange relation in Europe.

In conclusion, the results demonstrated a optimistic relationship within US premium rate and market capitalisation. The estimation of the US premium rates was sure; implying that an expand in US premium rates will prompt an ascent in business sector capitalisation. The US investment rates sign was required to be negative yet comes about have demonstrated the positive. This may be the way that developing markets like United Kingdom are still seen as alluring by speculators paying little mind to other macroeconomic elements, for example, world premium rates.

Indicative tests on the model demonstrated a steady and strong model. The Q-detail test demonstrated that there was no serial association in the residuals. Issues of ARCH were additionally killed by the GARCH model. In any case, the typicality test demonstrated that the residuals were not typically disseminated and this situation is confronted by a few studies.

\section{Policy implications and recommendations}

The discoveries from this study have various strategy suggestions. Firstly, the frail unpredictability transmission from the GBP to stock exchange may be characteristic of expanded utilization of supporting instruments by firms on the LSE. Additional supporting instruments needs to be placed set up to guarantee the disposal of negative impacts of GBP unpredictability. These supporting instruments ought to be proficient and they ought not contort the ordinary working of the LSE. There has been sizeable proof in backing of hypotheses recommending that relative value instability gives motivations to ambitious people to embrace more "flexible" however less beneficial generation advances, empowering them to oblige money volatility8. Supporting operations are, on occasion, expensive and can diminish the execution of the organizations.

Besides, Since the United Kingdom $\mathrm{n}$ stock exchange is not by any stretch of the imagination presented to the negative impacts of money unpredictability. Important arrangement creators in government can utilize swapping scale as an approach instrument to pull in remote portfolio speculation. In addition, the capacity of the LSE to support against the negative impacts of cash instability could be utilized as a device to pull in outside financial specialists to stocks. The capacity of securities exchanges to pad against macroeconomic vulnerabilities has been connected with created nations' stock exchanges, for example, the United States and United Kingdom. Be that as it may, this has additionally been seen, in this study, and this demonstrates that the LSE could be showcased as a safe business for remote financial specialists. The feeble unpredictability transmission from the conversion scale business to money markets shows that there is prospect for remote speculators to differentiate their interests in these two businesses.

Thirdly, The LSE needs to keep up its co-operation with world class stock exchanges, for example, the LSE. This may be one of the reasons the LSE can pad negative impacts of coin unpredictability. Macroeconomic overflows from created nations are normally difficult to manage however in the event that there is some joining between the LSE and created nations, news about any conceivable improvements in these business sectors will achieve the LSE quick and measures to manage any conceivable impacts of these macroeconomic advancements will be placed set up route before the businesses are influenced.

In conclusion, Investors, brokers and portfolio chiefs still need to be vigilant on the overflows from the remote conversion standard into stocks. In spite of the fact that there is a feeble relationship between GBP instability and the share trading system in United Kingdom, this does not so much imply that speculators and portfolio chiefs require not screen the improvements between these two variables. Different methodologies to ensure money markets from the hurtful impacts of cash instability need to be brought into stocks. These instruments would then be utilized to further fence against trade hazard. Conversion standard incited instability is a pressing issue in United Kingdom and numerous different nations that have adaptable swapping scale administrations.

\section{Possible regions for further research}

Swapping scale unpredictability is at the center of the boiling over verbal confrontation on the execution of conversion standard administrations. This worry was fortified by the huge developments in ostensible trade rates that portrayed world budgetary markets since the move to an oversaw skimming conversion scale framework in 1973. A significant concern of approach producers at the downfall of the Bretton Wood framework is the outcome of swapping scale instability saw to be a noticeable peculiarity of an adaptable conversion standard framework. Money unpredictability has respectable ramifications in the monetary markets, particularly the stock exchange.

The GBP has been the most unstable among rising monetary standards over the recent years. United Kingdom 's late measures to diminish the GBP's unpredictability haven't had a craved effect as the 
cash's vacillation is powered by worldwide financial shakiness and capital inflows from created nations (Davies, 2010). United Kingdom has encountered significant and proceeded with money unpredictability amid the recent years notwithstanding of solid monetary basics. Pretorius and de Beer (2002) note that the stressing instability of the GBP brought about the erGBP of the Myburgh Commission of investigation into the devaluation of the GBP. Policymakers and scholastics have progressively pondered about the way of the money instability emergencies, the variables in charge of their spread and especially whether a nation with apparently suitable residential and outer essentials can experience the ill effects of cash emergency.

"The joining of the LSE into the world business has been supported by the proceeded with development and improvements it has been making. Mboweni contends that amid 2001, the LSE entered into two concurrences with the London Stock Exchange (LSE) to accommodate co-operation in admiration of information dispersal and the likelihood of remote participation and double essential postings on both trades. The relations with the London Stock Exchange (LSE) have been solid and have to a great extent enhanced the operations on the LSE. The LSE Tradelect, which is the LSE's completely robotized exchanging framework, is worked under the permit from the LSE. These and different improvements have helped the LSE's worldwide standing and this has enhanced LSE's effectiveness and its risks of pulling in financial specialists both generally and abroad. This has made it to be one of the best performing stock trades on the planet.

It is recognized that United Kingdom 's ostensible conversion scale unpredictability is among the most astounding of all merchandise exporters and developing markets and that, in time of "unnecessary instability", money developments don't go about as a stun absorber reflecting changes in relative costs, however as a "wellspring of powerlessness". Notwithstanding real upgrades in the organization of financial and fiscal approach, money instability discourages speculators in tradable products and administrations outside of the merchandise segment. "The GBP remains to some degree unstable; however the level of instability has been decreased. At present, the relative instability is joined by a coin that is over-esteemed as in monetary assets are redirected into limited territories of venture, establishing a shaky framework for what's to come"

Knedlik kept up that expanded unpredictability of trade rates in developing markets is additionally ascribed to the more modest size of their economies and therefore the littler size of the business for their money. Higher swapping scale instability in developing business sector nations is in this way a reasonable desire and reflects principal contrasts in the structure of economies. Regardless, it is evident that a real snag for effective arranging in the business area, and the powers would have wanted to have more prominent conversion scale soundness. Yet, under the current circumstances, conversion scale variances are most likely unavoidable. Unstable money related streams now and then created by advancements in different monetary forms make the accomplishment of swapping scale steadiness almost unimaginable (Van de Merwe and Mollentze, 2009).

Benita and Lauterbach (2004) demonstrated that conversion standard unpredictability have genuine financial expenses that influence value steadiness, firm benefit and a nation's solidness. Swapping scale unpredictability has suggestions for the monetary arrangement of a nation particularly money markets. Conversion standard instability produces quality of vulnerability as the fluctuation of expected benefits climbs and its net present worth falls. Stock exchange assumes an extremely essential part in evaluating financial states of any nation through enhanced stock returns normally meant by higher benefit to firms. This thusly causes financial development and the other way around. Essentially stock trade business serves as a channel through which surplus trusts are moved from Lender-Savers to Borrower-Spenders who have deficiencies of stores. In view of this reason, instability in stock costs can essentially influence the execution of the budgetary area and the whole economy.

Also, cash instability prompts the issues of conversion scale hazard. Swapping scale danger, or money danger, is the hazard that a business' operations or a venture's worth will be influenced by progressions in return rates. Case in point, if cash must be changed over into alternate money to make certain venture, changes in the estimation of the coin with respect to the US dollar will influence the aggregate misfortune or increase on the speculation when the cash is changed over back. This danger typically influences organizations yet it can likewise influence singular financial specialists who make global speculations. Subsequently trade danger is higher under states of conversion scale unpredictability.

The majority of the studies that looked to analyze the relationship between conversion scale unpredictability and the share trading system, including this one, focused on utilizing month to month information to inspect the relationship that exists between the two variables. Then again, it must be noted that day by day information or week by week information give more helpful comes about that month to month information. It is along these lines, recommended that the centrality of this present study's results could be enhanced by applying day by day or week by week information.

Utilizing more incessant perceptions better catches flow of conversion scale and stock exchange interrelationships.

\section{References}

1. Branson W, Halttunen $H$, Masson $P$ (1977) Exchange rate in the short run: The dollar Deutsche mark rate, European Economic Review 10: 303-324.

2. Fama EF, French RK (2004) The Capital Asset Pricing Model: Theory and Evidence.

3. Saleh G (2009) The Dynamic Relation Between Stock Prices and Exchange Rates in Egypt, Saudi Arabia and UAE. United States, UMI.

4. Choi JJ, Papaioannou MG (2009) Credit, Currency, or Derivatives: Instruments of Global Financial Stability. U.K, Emerald Group Publishing.

5. Aggarwal R (1981) Exchange Rates and Stock Prices: A Study of the US Capital Markets under Floating Exchange Rates, Akron Business and Economic Review.

6. Soenen LA, Hennigar ES (1988) An Analysis of Exchange Rates and Stock Prices: The U.S Experience between 1980 and 1986

7. Bahmani OM, Sohrabian A (1992) Stock Prices and the effective exchange rate of the dollar, Applied Economics 24: 459-464.

8. Bhattacharya B, Mukherjee J (2003) Causal Relationship Between Stock Market and Exchange Rate. Foreign Exchange Reserves and Value of Trade Balance: A Case Study for India.

9. Chow EH, Lee WY, Solt MS (1997) The exchange rate risk exposure of asse returns.

10. Solnik B (1987) Using financial prices to test exchange rate models: A note. J Financ, 42: 141-149

11. Franck P, Young A (1972) Stock Price Reaction of Multinational Firms to Exchange Realignments.

12. Pilbeam K (1998) International Finance. 2nd ed. UK, Basingstoke: Mac Adjas C, Harvey SK, Agyapong D (2008) Effect of Exchange rate volatalitity on the Ghana stock exchange. African Journal of Accounting, Economics and Banking research. 
Citation: Hossain SA (2015) An Empirical Analysis to Assess the Impact of Inconsistency of Exchange Rate on Share Market: A Case Study of London Stock Exchange. J Bus Fin Aff 4: 154. doi:10.4172/2167-0234.1000154

Page 16 of 16

13. Friedman M (1988) Money and the Stock Market, Journal of Political Economy 96: 221-245.

14. Stavárek D (2004) Linkages between Stock Prices and Exchange Rates in the EU and the United States, Cech Republic, Silesian University in Opava School of Business Administration in Karviná Department of Finance.

15. Aydemir O, Demirhan E (2009) The Relationship between Stock Prices and Exchange Rates Evidence from Turkey, Int Res J Financ Eco, 23: 207-215.

16. Welfens PJ, Ryan C (2007) Financial Market Integration and Growth: Structural Change and Economic Dynamics in the European Union. London, Springer.

17. Richards ND, Simpson J, Evans J (2009) The Interaction Between Exchange Rates and Stock Prices: An Australian Context, Int J Eco Financ 1: 3-23.

18. Kasper LJ (1997) Business Valuations: Advanced Topics. USA, Green wood Publishing.
19. Mandal BN (2009) Global Encyclopaedia of Welfare Economics: The Principle of Population. India, Singh Global Vision for Publishing

20. Herekar H (2006) Capital Asset Pricing Model (CAPM) for Dummies.

21. Taylor (2005) An Empirical Evaluation of the Capital Asset Pricing Model.

22. Vernimmen P, Quiry P, Fur Y, Dallochio M, Salvi A (2005) Corporate Finance: Theory \& Practice. England, John Wiley and Sons.

23. Nieh CC, Lee CF (2001) Dynamic relationship between stock prices and exchange rates for G-7 countries, The Quarterly Review of Economics and Finance 41: 477-490.

24. Saunders M, Lewis P, Thornhill A (2007) Research Methods for Business Students, Harlow: Pearson Education Ltd. 